IZA DP No. 4373

Producer Protection Legislation and Termination Damages in the Presence of Contracting Frictions

Steven Wu

August 2009 


\title{
Producer Protection Legislation and Termination Damages in the Presence of Contracting Frictions
}

\author{
Steven Wu \\ Purdue University \\ and IZA
}

Discussion Paper No. 4373

August 2009

IZA

P.O. Box 7240

53072 Bonn

Germany

Phone: +49-228-3894-0

Fax: +49-228-3894-180

E-mail: iza@iza.org

Any opinions expressed here are those of the author(s) and not those of IZA. Research published in this series may include views on policy, but the institute itself takes no institutional policy positions.

The Institute for the Study of Labor (IZA) in Bonn is a local and virtual international research center and a place of communication between science, politics and business. IZA is an independent nonprofit organization supported by Deutsche Post Foundation. The center is associated with the University of Bonn and offers a stimulating research environment through its international network, workshops and conferences, data service, project support, research visits and doctoral program. IZA engages in (i) original and internationally competitive research in all fields of labor economics, (ii) development of policy concepts, and (iii) dissemination of research results and concepts to the interested public.

IZA Discussion Papers often represent preliminary work and are circulated to encourage discussion. Citation of such a paper should account for its provisional character. A revised version may be available directly from the author. 
IZA Discussion Paper No. 4373

August 2009

\section{ABSTRACT \\ Producer Protection Legislation and Termination Damages in the Presence of Contracting Frictions}

This study models producer protection legislation that would grant growers the right to claim damages (PPLD) if their contracts are prematurely terminated. In the absence of contracting frictions that prevent contractors from redesigning contracts to accommodate exogenous policy changes, PPLD would not be distortionary or redistributive. If contracting frictions exist, then PPLD would have efficiency and redistributive effects, though the direction and magnitude depends on the size of PPL damages vis-à-vis expected damages under existing contract law. This study clarifies the conditions under which PPLD would decrease efficiency and protect growers.

JEL Classification: Q12, Q18, K12, D82, D86

Keywords: contracts, moral hazard, agricultural policy, producer protection legislation, contract law

Corresponding author:

Steven $\mathrm{Wu}$

Department of Agricultural Economics

Purdue University

403 West State Street

Krannert Bldg.

West Lafayette, IN 47906

USA

E-mail: sywu@purdue.edu 
This study investigates the potential efficiency and distributional effects of statutory intervention that would impose termination damages on agricultural production contracts. Recent legislation aimed at protecting growers have included stipulations that allow growers to claim damages from contractors if contracts are prematurely terminated. A model state law called the Producer Protection Act includes a section that grants growers the right to damages. All or parts of this act have been proposed in Georgia, Indiana, Iowa, Kansas, Kentucky, Mississippi, Missouri, Nebraska, North Carolina, North Dakota, Oklahoma, and South Dakota.

The typical justification for such legislation is that growers operating under production contracts often make large fixed investments in modern production facilities. ${ }^{1}$ These investments are often required by the contractor when a grower is entering into a production contract or is seeking continuation of an existing contract. Because some of these production facilities must be customized to the specific requirements of contractors, the facilities can be relationship-specific and have little to no alternative use. At the same time, contractors have been known to prematurely terminate or fail to renew contracts, leaving growers with unpaid debts that were used to finance the facilities. ${ }^{2}$

While farm advocates continue to promote legislation to protect growers, agricultural economists have conducted relatively few formal studies of grower protection legislation (Wu 2006). Most published articles tend to be descriptive commentaries, although the author is aware of two formal studies. The first is the study by Lewin-

\footnotetext{
${ }^{1}$ Cunningham (2005) reports that broiler houses can exceed $\$ 170,000$ per house and usually a minimum of two houses are needed. Loans are usually amortized over 15 years and the life of houses can reach 30 years. ${ }^{2}$ Broiler growers typically operate under flock-to-flock contracts. Hog farmers often receive 5 to 10 year contracts but these contracts are still shorter than the duration of the loan or the expected life of the houses.
} 
Solomons (2000), which investigates direct restrictions on termination. LS models these restrictions as a reduction in the probability of a grower being terminated. This study, in contrast, does not investigate direct restrictions and instead focuses on termination damages. The second article by Lee, $\mathrm{Wu}$ and Fan (2008) is more closely related to this article because it also focuses on damages. However, there are two important differences between the LWF article and this article. First, LWF discuss the effects of moving from an initial situation where termination does not result in damage awards to a post-legislation scenario where termination always results in damages. However, in practice, existing contract law may, in some circumstances, award growers with damages even in the absence of producer protection legislation. This paper takes existing contract law as given, but introduces the possibility of enforcement errors which might make it difficult for growers to recover damages. The value of producer protection legislation (henceforth PPL damages or PPLD) is that PPLD can reduce these enforcement errors. Hence, the relevant benchmark for PPLD is not a world free of termination damages, but rather a second best world where existing contract law functions imperfectly. Second, LWF assume that the level of relationship-specific investments and is exogenously determined. This paper examines both exogenous and endogenous cases. The endogenous case is important as some researchers suggest that, in some circumstances, processors can incentivize growers by requiring growers to make excessive relationship-specific investments (e.g. LewinSolomons 2000; Vukina and Leegomonchai 2006). Moreover, in cases where growers earn rents, as in efficiency-wage or limited liability models, contractors can extract away 
these rents by raising the level of investment; that is, the investment can be used as an implicit "entry fee" (e.g. Carmichael 1985) that reduces the cost of incentive provision.

The major findings of this paper are as follows. First, if there are no contracting frictions, then no economic distortions emerge under PPLD. Intuitively, even if PPLD increases expected liabilities of contractors, contractors can factor future liabilities into the initial contract price. Thus, overall contracting costs are unaffected. Second, if there are contracting frictions, perhaps caused by credit market imperfections or grower wealth constraints, then contractors are constrained in their ability to redesign contracts to offset changes in expected liabilities. In this case, PPLD might have both distributional and efficiency effects, but the direction and magnitude of the effects depend on the size of PPL damages relative to the size of expected damages under existing law. Specifically, when enforcement errors are high so that it is costly for growers to recover damages under existing law, then expected damages are low under existing law. In this case, PPLD will likely increases contractors' expected liabilities making it more expensive for contractors to implement incentives for high performance. At the same time, growers benefit as their expected profits increase. In contrast, when enforcement errors are low and courts are likely to award large damages under existing law, then PPLD might actually improve efficiency while reducing grower welfare. Third, even when investments are endogenous, contractors are unlikely to impose an excessive level of relationship-specific investments on growers. Intuitively, the contractor is the residual claimant of the total surplus from the contractual relationship, minus any cost of incentive provision. Hence, the processor wants to maximize total surplus while minimizing the cost of incentive provision. While 
increasing the level of investment can act as an implicit "entry fee" and reduce the cost of incentive provision, it nevertheless reduces total surplus, as total surplus is joint profits minus investment costs. Moreover, excessive investments might also increase expected liabilities because damages might depend on investments. The net effect is that there is a negative benefit to the processor of marginally increasing the level of investment beyond the technologically required level.

\section{New Damages Legislation versus Existing Contract Law}

Before discussing the formal model, it is important to discuss institutional details and enforcement errors that make it difficult for growers to recover damages under existing contract law. This provides justification for the assumptions used in the model.

Even in the absence of PPLD, contract law suggest that courts can award either reliance or expectation damages where reliance damages compensate the victim of breach in an amount that leaves him as well off as he would be had he not contracted in the first place, while expectation damages would leave the victim as well off as he would be if the contract were honored. However, many law and economics scholars recognize that contract law works imperfectly in that it may be costly for a victim to bring a dispute to court and recover damages. Such "enforcement errors" can reduce the level of expected damages and therefore erode the power of contract law to incentivize optimal behavior. ${ }^{3}$

There are reasons to believe that enforcement errors might be non-trivial in agricultural production contracting. First, some contracts contain arbitration clauses, which may preclude growers from suing for damages under the Uniform Commercial

\footnotetext{
${ }^{3}$ The reader should not confuse expected damages with expectation damages. Expectation damages is a legal concept describing a particular level of damages.
} 
Code (UCC). For example, in 2002, Tyson severed relationships with 132 hog growers in Arkansas and Oklahoma. The growers sued for damages but Tyson alleged that a mandatory arbitration clause in the contracts did not allow the growers to sue (Moeller 2003). Second, even when farmers have access to courts, how judges interpret laws can differ so there is no guarantee of success for growers. Moreover, the probability of success in lawsuits can depend on whether growers are determined to be "merchants" and courts are divided about this issue (Hamilton 1995). Third, if a contract is short term, then the contract may be similar to an employment-at-will contract, which makes it difficult for growers to claim damages. Even if growers argue that oral agreements and implied actions (e.g. long term investments) make agreements long term contracts, courts may not agree. PPLD might remedy this by specifying that contract length must match the life of the assets. Fourth, courts may have trouble determining the size of damages. If damages are difficult to assess, courts may refuse to award "speculative damages." Finally, under the UCC, growers may have difficulty recovering damages because production contracts do not involve a sale of goods. The UCC generally applies to contracts for the sale of goods and not for services such as raising livestock for another party (Hamilton 1995). In short, the process of trying to recover damages under existing law can be difficult and time consuming. Thus, for modeling purposes, it is reasonable to assume that the average grower will receive damages upon termination only with probability less than one.

One objective of PPLD is to eliminate ambiguities surrounding growers' rights to claim damages so that enforcement errors are minimized. Most proposed PPL also specify a level of damages that is equal to reliance damages; i.e., if growers are terminated, then 
"Damages shall be based on the value of the remaining useful life of the structures, machinery or equipment involved" (Section 8 of the Producer Protection Act).

The above discussion suggests that, for modeling purposes, there are two channels through which PPLD might operate. First, there will be a reduction in enforcement errors. Second, PPL damages will be set at a level that permits growers to recover the investments that they made to meet contract requirements.

\section{The Model}

The model is based on a principal-agent framework of moral hazard where the agent exhibits limited liability. Principal-agent models are useful for analyzing livestock contracts (e.g. Knoeber 2000). The model also shares features with classic law and economics models that analyze damages for breach of contract (e.g. Barton 1972). The assumptions are that a processor (principal) contracts with a grower (agent) in order to produce a commodity that serves as an input for a final food product. The processor's revenue from the food product depends on the quality of the input commodity. The word "quality" serves as a proxy for any performance factor that enhances the processor's revenue. Thus, "quality" can be replaced with any other value-adding performance factor such as on-time deliveries, niche characteristics, low levels of pathogens, etc.

For simplicity, quality can only assume two levels: "high" and "low." The processor's revenue is denoted by $R(y)=k y$ where $y$ is quality and $k \geq 0$ is a scalar. When quality is high, it assumes some positive value $y>0$ whereas when it is low, $y=0 .{ }^{4}$

\footnotetext{
${ }^{4}$ Assuming zero revenue under low quality greatly simplifies the notation. Under the modeling assumptions outlined in this section, defining revenue under low quality to be some positive number less than $y$ would add little additional insight at the cost of increased notational burden.
} 
Moreover, quality is assumed to be stochastically related to "effort" exerted by the grower where effort is unobservable to the processor so there is moral hazard.

The principal-agent model is based on a risk neutral processor and a risk neutral grower who faces a limited liability (LL) constraint. LL constraints have both theoretical and practical appeal (e.g. Innes 1990; Demougin and Garvie 1991). On the practical side, LL constraints act as "payment floors" that prevent the processor from promising excessively low or negative payments in some states of the world. This constrains processors from using "sticks" or severe punishments to motivate growers. In practice, agricultural contracts implicitly contain payment floors because contracts with "negative payments" where growers pay processors in some states of the world are unheard of. While in principle negative payments can be specified as part of an optimal contract, contracting frictions, such as wealth constraints, might make negative payments infeasible. In some cases, even positive but low payments might be ruled out due to credit market constraints. For instance, some lenders will not approve loans unless the contract guarantees the grower at least some minimal payment in all states of nature. ${ }^{5}$

On the theoretical side, it is well known that the moral hazard problem is trivial if there is no agent risk aversion or LL constraints, as first best can always be achieved by making the agent the residual claimant. Thus, one needs to impose either LL constraints or risk aversion on the agent for moral hazard to matter. ${ }^{6}$ The LL model is used in this article

\footnotetext{
${ }^{5} \mathrm{~A}$ hog contractor that the author spoke to suggested that they could not "punish growers" by reducing their payments below $\$ 34$ for feeder to finish space of 7.5 sqft per pig. If deducts were used, the lenders would not approve of loans to growers for constructing production facilities.

${ }^{6}$ This is not to imply that risk aversion and limited liability are perfect modeling substitutes for all situations. There are some well known qualitative differences. For example, under limited liability the agent cares less
} 
because it has two advantages over the risk aversion model; namely, that it is (1) easier to solve, and (2) it leaves open the possibility that growers (agents) can earn rents above reservation levels. That is, if the principal wants to implement stronger incentives, it has to provide increasingly larger bonuses (deducts are ruled out), which increases expected rents of the agent. The existence of rents makes the LL model more attractive for investigating policy issues with redistributive effects. Moreover, Allen and Lueck (1995) argue that risk neutral models with transactions costs may be better suited for modeling agricultural problems than contracting models with risk aversion. Knoeber (2000) suggests that risk costs may not be the primary factor in livestock contracts in the U.S.

The model assumes that a processor offers a contract conditional on the grower making or sharing in a large upfront investment to build/upgrade production facilities with the latest technology. Thus, the processor must promise the grower profit of a sufficient size to ensure that the grower's participation constraint is satisfied. If the processor terminates the grower prematurely, then the grower suffers losses, as he would be left with debt and no future profit. Assume that the total monetary cost of the investment is denoted by $I$ and that the processor requires the grower to bear at least a share, if not all, of the cost. Thus, let $I=I_{P}+I_{G}$ where $I_{P}$ and $I_{G}$ denote the processor and grower's share of the investment cost, respectively. The investment is also assumed to be relationship-specific so that its salvage value is zero outside the relationship. Assuming full asset specificity does not reduce the generality of the results but simplifies notation. ${ }^{7}$ The paper analyzes both 
the case when $I$ is exogenous (e.g. if assets are discrete/indivisible and the parties are price takers in the market for assets) and the case when $I$ is endogenous. In the latter case, the processor can choose the level of $I$ subject to some minimal technology constraint $I \geq \underline{I}$. Moreover, the processor can choose the share of the cost borne by the grower, $I_{G}$.

The timing of the game is as follows. In stage 1, the processor offers a contract to the grower and specifies $I$ (if endogenous), $I_{G}$, and $I_{P}$. In stage 2, prior to production, the state of nature reflecting market conditions is revealed. In the bad state, the processor views continuation of the contract to be unprofitable and terminates the contract. The grower suffers a loss in the amount $I_{G}$ because $I$ is relationship-specific. If the good state of nature occurs, the game continues into stage 3 , the production stage. The grower exerts effort, which is followed by the realization of quality, which in turn triggers contract payments to the grower.

The realization of the state of nature in stage 2 is assumed to be verifiable and allows for non-performance related contract termination. Bad states of the world (e.g. adverse economic conditions) are common in many industries and can induce firms to close plants, lay off workers and/or terminate suppliers. The probability of a good state is denoted by $v$. In the good state, it is assumed that the scalar $k$ in the processor's revenue function takes the value $k=1$ so that $R(y)=k y=y$. The probability of the bad state is $1-v$ and results in $k=0$ so that $R(y)=0$. Thus, an exogenous event can cause the processor's revenue to vary independently of grower performance. Total surplus (revenue minus all costs) is negative in the bad state of nature. Because the grower is promised positive stage 3 profit downstream goods. Thus, asset specificity may ultimately depend on the downstream product portfolio. 
to offset the cost of the upfront investment, negative surplus in the bad state implies that the processor makes negative profits. Hence the processor prefers to terminate the contract in the bad state. Assuming that the grower might be terminated before the production stage may seem unrealistic. However, allowing for some production before termination is not essential - what is essential is that the grower might not receive promised compensation and this is captured by the model. Similarly, allowing for multi-period contracting would only increase complexity while offering little additional insight.

If the contracting game reaches stage 3 , the grower exerts unobservable effort which is stochastically related to quality. Quality is assumed to be observable and verifiable so that it can be included in the contract. Effort is denoted by $e \in\{0,1\}$ and the cost of effort is given by ce where $c>0$. When the grower exerts high effort $(e=1)$, then the probability of high quality is $p_{h}$. When the grower exerts low effort $(e=0)$, then the probability of high quality is $p_{l}=p_{h}-\Delta p$ where $p_{h}>\Delta p>0$. Once quality is realized, the processor makes contractually specified payments $\mathbf{w}=\left(w_{l}, w_{h}\right)$ where $w_{x}$ is the payment to the grower contingent on whether quality is high $(x=h)$ or low $(x=l)$. The LL constraint is incorporated with the restriction $w_{x} \geq 0$. Reservation profits for both the processor and grower are assumed to be zero in the model.

The final assumption is $v\left(p_{h} y-c\right)-I \geq \max \left\{v p_{l} y-I, 0\right\}$. This assumption implies that contract acceptance and high effort lead to first best ex ante efficiency. ${ }^{8}$ In the special case of $v p_{l} y-I \geq 0$, the above condition reduces to $\Delta p y \geq c$. These assumptions are

\footnotetext{
${ }^{8}$ The condition $v\left(p_{h} y-c\right)-I \geq \max \left\{v p_{l} y-I, 0\right\}$ implicitly assumes that there is efficient ex post breach which yields a surplus of zero in the bad state. The alternative to breach is continuation which is ex post inefficient as it yields negative surplus under the modeling assumptions.
} 
reasonable because if high quality does not create sufficient value, then there is no reason to contract in the first place. Thus, these assumptions allow us to focus on the most interesting case where high effort is consistent with social welfare maximization.

Conditions $v\left(p_{h} y-c\right)-I \geq 0$ and $\Delta p y \geq c$ characterize first best outcomes and serve as important benchmarks for subsequent analyses. ${ }^{9}$ It is important to note that the processor's objectives may not be consistent with social welfare maximization, as the processor's profit is social surplus minus LL rents (to be made precise shortly) paid to the grower to incentivize effort. Thus, the processor might choose to minimize LL rents rather than pursue high effort and social welfare.

\section{Optimal Contracting under Existing Contract Law}

This section characterizes efficiency and distribution under existing contract law. The results of this section provide a benchmark for assessing PPLD in the next section. The analysis begins by describing contracting outcomes in the shadow of existing contract law where courts might award either reliance or expectation damages if a lawsuit for contract breach is successful. However, due to enforcement errors, there is no guarantee that a grower will pursue or win a lawsuit. To model this, let $s \in[0,1]$ denote the probability that a grower will receive damages if terminated. Thus, even if a court awards damages $D$ under a successful lawsuit, expected damages ex ante is $s D$. When $s$ is close to 1 , enforcement errors are low but when $s$ is close to zero, enforcement errors are high.

The processor's objective is to maximize expected profit through the design of an optimal incentive contract. That is, the processor decides on a preferred effort level and

\footnotetext{
${ }^{9}$ These conditions are compatible with the assumption $y=0$ under low quality.
} 
then designs a menu of contract payments $\mathbf{w}=\left(w_{l}, w_{h}\right)$ that induce the grower to choose the processor's preferred effort level. Moreover, if the bad state of nature is realized, the processor must choose to either terminate and pay damages with probability $s$, or to continue and operate at a loss. Therefore, the processor solves

(1) $\max _{\mathrm{w} ;,, I_{P}, I_{G}} v\left\{\left[e p_{h}+(1-e) p_{l}\right]\left[y-w_{h}\right]-\left[1-e p_{h}-(1-e) p_{l}\right] w_{l}\right\}-I_{P}+(1-v) \max \left\{-s D, \pi_{e}^{b}\right\}$

subject to the grower's incentive compatibility (IC), participation, and LL constraints. Moreover, $I=I_{P}+I_{G}$ must hold. The last term in (1) indicates that the processor must choose between terminating and facing expected damages, $s D$, or not terminating and earning continuation profit $\pi_{e}^{b}$, where

$$
\pi_{e}^{b}=-\left[e p_{h}+(1-e) p_{l}\right] w_{h}-\left[1-e p_{h}-(1-e) p_{l}\right] w_{l}<0 .
$$

Define the binary variable

$$
i=\left\{\begin{array}{ll}
1 & \text { if } \max \left\{-s D, \pi_{e}^{b}\right\}=-s D \\
0 & \text { if } \max \left\{-s D, \pi_{e}^{b}\right\}=\pi_{e}^{b}
\end{array} .\right.
$$

Then the grower's participation constraint, which requires the grower's expected profit under the contract to be at least as high as his reservation payoff of zero, is

$$
[v+(1-v)(1-i)]\left\{\left[e p_{h}+(1-e) p_{l}\right] w_{h}+\left[1-e p_{h}-(1-e) p_{l}\right] w_{l}-c e\right\}+(1-v) i s D-I_{G} \geq 0 .
$$

Assume for now that $I$ is exogenously determined. Therefore, the processor only needs to determine $I_{G}$, which will also pin down $I_{P}$. The endogenous case is examined later.

The grower's IC constraint specifies the condition under which a rational grower chooses high effort ( $e=1$ ) over low effort $(e=0)$. The grower chooses high effort over low effort if and only if his expected profit is higher under high effort; that is, 


$$
\begin{aligned}
{[v+(1-v)(1-i)]\left\{p_{h} w_{h}+\left[1-p_{h}\right] w_{l}-c\right\}+(1-v) i s D-I_{G} \geq } \\
{[v+(1-v)(1-i)]\left\{p_{l} w_{h}+\left[1-p_{l}\right] w_{l}\right\}+(1-v) i s D-I_{G} }
\end{aligned}
$$

which simplifies to

$$
w_{h}-w_{l} \geq \frac{c}{\Delta p} .
$$

Inequality (6) is the IC for implementing $e=1$ but an optimal incentive contract should satisfy (6) with equality. ${ }^{10}$ Thus, optimal incentives require

$$
w_{h}=w_{l}+\frac{c}{\Delta p}
$$

where $\frac{c}{\Delta p}$ represents the performance bonus for high effort. Finally, the LL constraint is straightforward as it simply restricts all payments to $w \geq 0$.

If the processor wants to implement $e=1$, two cases must be considered. In case (i), $s D$ is low enough that the processor finds it more profitable to terminate and pay damages rather than to continue in the bad state. In case (ii), $s D$ is so high that the processor will choose continuation even in the bad state. The extended analysis of both cases is in the $\mathrm{Wu}(2010)$. It is shown in there that, under existing contract law, which specifies reliance or expectation damages, the processor always terminates in the bad state. Thus, we can focus on case (i) for the remainder of the paper.

To determine the optimal level of $I_{G}$, substitute $e=1, i=1$, and (7) into (4) to get

$$
u_{e=1}=v\left[w_{l}+\frac{p_{l} c}{\Delta p}\right]+(1-v) s D-I_{G} .
$$

\footnotetext{
${ }^{10}$ It is common in the contracting literature to impose weak rather than strong inequality. As Laffont and Martimort (p. 37, footnote 9, 2000) point out, strict preference is easily obtained at an $\varepsilon$ cost to the principal.
} 
When (8) is strictly greater than zero, then the grower earns rents. But whether rents exist or not depends on the size of $I_{G}$. When $I_{G}$ is large, the processor must compensate the grower accordingly to ensure that (8) is non-negative to satisfy the participation constraint. This requires $w_{l}>0$, which means that the LL constraint does not bind. But the processor never sets $w_{l}$ so high that the grower is left with rents.

On the other hand, when the size of $I_{G}$ is "low," then the grower's expected profit is large even with a relatively small $w_{l}$. But a low $w_{l}$ implies that the LL constraint $w_{l} \geq 0$ is close to binding leaving the processor with little slack to extract rents. If the LL rent is large enough, then the grower's expected profit is positive even with $w_{l}=0$.

REMARK 1: Suppose that the processor wants to implement $e=1$ in the shadow of existing contract law. Then the grower earns rents if $v \frac{p_{l} c}{\Delta p}+(1-v) s D>I_{G}$.

Proof: See the $\mathrm{Wu}$ (2010) for proofs of all remarks and propositions.

Remark 1 precisely identifies the grower rent thresholds for $I_{G}$. These thresholds depend on exogenous parameters $v$ (the probability of the good state), $c$ (the marginal disutility of effort), $\Delta p$ (the gain in probability of high quality from choosing high effort), $s$ (the probability that $D$ will be paid), $D$, and $p_{l}$ (the probability of high quality given low effort). If $v \frac{p_{l} c}{\Delta p}+(1-v) s D \leq I_{G}$ then the grower earns no rents because the processor can extract it away by setting $w_{l}=\frac{I_{G}}{v}-\frac{(1-v)}{v} s D-\frac{p_{l} c}{\Delta p} \geq 0$. But if $v \frac{p_{l} c}{\Delta p}+(1-v) s D>I_{G}$, then only $w_{l}=0$ is possible given the LL constraint. Thus, the optimal contract yields payments: 
(9) $\quad w_{l}=\max \left\{0, \frac{I_{G}}{v}-\frac{(1-v)}{v} s D-\frac{p_{l} c}{\Delta p}\right\}$

and

$$
w_{h}=\max \left\{0, \frac{I_{G}}{v}-\frac{(1-v)}{v} s D-\frac{p_{l} c}{\Delta p}\right\}+\frac{c}{\Delta p} .
$$

In order to determine the optimal choice of $I_{G}$, note from Remark 1 that the choice of $I_{G}$ can affect the rents that the processor must pay the grower in order to provide incentives. Thus, over the interval $\Gamma^{-}=\left[0, \frac{v p_{l} c}{\Delta p}+(1-v) s D\right)$, the processor will increase $I_{G}$ in order to reduce rents. But over the interval $\Gamma^{+}=\left[\frac{v p_{l} c}{\Delta p}+(1-v) s D,+\infty\right), I_{G}$ is high enough such that rents are eliminated so further increases in $I_{G}$ no longer benefit the processor. As a consequence, if $I \in \Gamma^{-}$, then the processor chooses $I_{G}=I$. However, if $I \in \Gamma^{+}$, then the constraint $I_{G} \leq I$ may or may not bind. While an increase in $I_{G}$ reduces the processor's investment $I_{P}$, this will be exactly offset by an increase in $w_{l}$ that is necessary to ensure that the grower's participation constraint is satisfied. The net effect is that the processor is indifferent about the level of $I_{G} \in \Gamma^{+}$so long as all constraints are met.

PROPOSITION 1: Suppose that the processor wants to implement $e=1$. Then if $I \in \Gamma^{-}$, then the optimal $I_{G}$ is $I_{G}=I$, but if $I \in \Gamma^{+}$, then the optimal $I_{G} \in \Gamma^{+} \cap \hat{I}$ where $\hat{\mathrm{I}}=\left\{I_{G}: I_{G} \leq I\right\}$. If the processor only wants to implement $e=0$, then $I_{G} \in \hat{\mathrm{I}}$. Proposition 1 is consistent with the stylized observation that processors often require growers to make substantial investments in new production facilities. Forcing growers to bear a large share of the cost serves to minimize LL rents, which lowers incentive costs. 
The optimal level of $I_{G}$ along with (9) and (10) can be substituted into the processor and grower objective functions to generate profits under the optimal contract. The value functions of processors and growers serve as useful benchmarks for subsequent analysis of distributional issues.

PROPOSITION 2: The expected profits of the processor and grower under effort levels $e=1$ and $e=0$ under existing contract law are:

a) $\pi_{e=1}=v\left[p_{h} y-c\right]-I-\max \left\{0, \frac{v p_{l} c}{\Delta p}+(1-v) s D-I\right\}$

$$
u_{e=1}=\max \left\{0, \frac{v p_{l} c}{\Delta p}+(1-v) s D-I\right\}
$$

b) $\pi_{e=0}=v p_{l} y-I$ $u_{e=0}=0$.

To assess efficiency, it is important to distinguish ex post from ex ante efficiency. Ex ante efficiency refers to the effort level preferred by the processor at the contract formation stage. Under the modeling assumptions, $e=1$ is ex ante efficient as it maximizes joint surplus. Hence, if a processor designs a contract that induces $e=1$, then the processor's action is consistent with ex ante efficiency.

In contrast, ex post efficiency has to do with whether the processor should terminate the contract after observing the state of nature. After observing the state of nature, the processor has to decide whether to continue with production under the contract that promises $w_{l}$ and $w_{h}$ or to terminate the contract and earn zero profit. The fixed investment $I$ is sunk and no longer matters in determining ex post efficiency. Given the modeling assumptions, it is ex post efficient for the processor to continue in the good state because $k=1$, which yields ex post surplus of either $p_{h} y-c>0$ or $p_{l} y>0$. But under the 
bad, $k=0$ so that continuation results in ex post surplus of either $-c<0$ or 0 , which is weakly inefficient. The extended analysis in $\mathrm{Wu}$ (2010) shows that, under existing contract law, which specifies either reliance or expectation damages, the processor always chooses to terminate in the bad state. Hence, existing contract law induces ex post efficiency. We can therefore focus on ex ante efficiency for the remainder of the paper.

Returning to ex ante efficiency, recall that contracting under high effort is always socially desirable and is characterized by the two conditions: $\Delta p y \geq c$ (high effort enhances expected surplus) and $v\left(p_{h} y-c\right)-I \geq 0$ (expected surplus is positive under high effort). However, because the processor's payoff is expected surplus minus LL rents, the processor might deviate from the socially efficient outcome if LL rents are high. The fundamental issue facing the processor when deciding to implement $e=1$ is whether the returns to high effort are worth the increase in LL rents.

PROPOSITION 3: Under existing contract law, the processor implements $e=1$ if

a) $\Delta p y \geq c+\max \left\{0, \frac{p_{l} c}{\Delta p}+\frac{(1-v)}{v} s D-\frac{I}{v}\right\}$

and

b) $v\left[p_{h} y-c\right]-I-\max \left\{0, \frac{v p_{l} c}{\Delta p}+(1-v) s D-I\right\} \geq 0$.

The two inequalities in Proposition 3 are essentially the processor's 'incentive compatibility" and "participation constraints" for choosing high effort. That is, if (a) is satisfied, then it is more profitable for the processor to choose $e=1$ instead of $e=0$. Note that (a) is directly comparable to the first best condition $\Delta p y \geq c$. When LL rents are large, there is a greater divergence between the two conditions so that the processor is less likely 
to choose high effort. Condition (b) acts like a participation constraint because if this inequality is violated, the processor earns negative profits and therefore does not offer a contract. LL rents causes (b) to diverge from the first best condition $v\left(p_{h} y-c\right)-I \geq 0$. However, it is important to emphasize that a large $I$ that minimizes LL rents is not always desirable. A large $I$ implies large fixed costs, which reduces surplus. Hence, while a large I may reduce LL rents, this must be weighed against the overall reduction in surplus.

\section{The Economic Impact of Damages Introduced by Producer Protection Legislation}

There are two channels through which PPLD could impact outcomes. First, PPLD eliminates, or at least reduces, enforcement errors by making it easier for growers to collect damages if their contracts are terminated. Second, because PPLD enables growers to claim damages equal to the remaining useful life of fixed investments, the legislation effectively sets $D=I_{G}$. For modeling purposes, it is convenient to make the simplifying assumption that, under PPLD, the enforcement error is eliminated so that $s=1 .{ }^{11}$ Also, because $D=I_{G}$ implies reliance damages, the processor always terminates in the bad state so that ex post efficiency is achieved. Setting $s=1$ and $D=I_{G}$, the grower's profit (8) changes to

$$
u_{e=1 P}=v\left[w_{l}+\frac{p_{l} c}{\Delta p}\right]-v I_{G} .
$$

The next remark is analogous to Remark 1, which identifies the grower's rent threshold.

REMARK 2: Suppose that the processor wants to implement $e=1$ in the shadow of PPLD.

Then the grower earns rents if $\frac{p_{l} c}{\Delta p}>I_{G}$.

\footnotetext{
${ }^{11}$ An alternative assumption is that $s<1$ but that it is greater under PPLD than under existing contract law. But this captures essentially the same point while increasing complexity.
} 
Remark 2 can be compared to Remark 1 to determine how the $I_{G}$ threshold at which the grower earns rents changes under PPLD. Comparing $v \frac{p_{l} c}{\Delta p}+(1-v) s D>I_{G}$ from Remark 1 to $\frac{p_{l} c}{\Delta p}>I_{G}$ from Remark 2, note that if the left-hand side of the latter inequality is greater than the left-hand side of the former inequality, then PPLD relaxes the threshold and growers are more likely to earn rents. It is easy to show that $\frac{p_{l} c}{\Delta p}>v \frac{p_{l} c}{\Delta p}+(1-v) s D$ if $s D<\frac{p_{l} c}{\Delta p}$. Under existing law, $D$ equals either expectation or reliance damages. Thus, only in the rare cases of no enforcement errors $(s=1)$ and expectation damages ( $D=\frac{p_{l} c}{\Delta p}$ ) under a binding LL would $s D<\frac{p_{l} c}{\Delta p}$ not be satisfied. To determine how PPLD might affect contract payments, note that if $\frac{p_{l} c}{\Delta p}>I_{G}$, then the LL constraint is binding and therefore $w_{l}=0$. However, if $\frac{p_{l} c}{\Delta p} \leq I_{G}$, then the grower earns no rents since the processor can set $w_{l}=I_{G}-\frac{p_{l} c}{\Delta p}>0$ to extract all rents. In general, the optimal contract yields payments:

$$
w_{l}=\max \left\{0, I_{G}-\frac{p_{l} c}{\Delta p}\right\}
$$

and

(13) $w_{h}=\max \left\{0, I_{G}-\frac{p_{l} c}{\Delta p}\right\}+\frac{c}{\Delta p}$.

One can compare (12) and (13) to (9) and (10) to determine how the introduction of PPLD might affect contract payments. Note that if PPLD is introduced and the LL constraint is 
not binding, then $w_{l}$ will change from $\frac{I_{G}}{v}-\frac{(1-v)}{v} s D-\frac{p_{l} c}{\Delta p}$ to $I_{G}-\frac{p_{l} c}{\Delta p}$. The latter is lower than the former if $I_{G}>_{S} D$; i.e., if the level of PPL damages exceeds expected liabilities under existing law, then the processor will price this into $w_{l}$. In essence, if the LL constraint is not binding, it is possible for the processor to "undo" any government policy through contract redesign. ${ }^{12}$ However, when LL constraints are binding, then there are contracting frictions that prevent the processor from undoing the regulation by lowering $w_{l}$. Thus, the grower's profit increases at the expense of the processor's.

In order to determine the optimal choice of $I_{G}$, it is trivial to show that Proposition 1 applies in the case of PPLD, with the exception that the sets $\Gamma^{-}$and $\Gamma^{+}$must be replaced with the sets $\Gamma_{P}^{-}=\left[0, \frac{p_{l} c}{\Delta p}\right)$ and $\Gamma_{P}^{+}=\left[\frac{p_{l} c}{\Delta p},+\infty\right)$.

PROPOSITION 4: Suppose that the processor wants to implement $e=1$. Then if $I \in \Gamma_{P}^{-}$,

then the optimal $I_{G}$ is $I_{G}=I$, but if $I \in \Gamma_{P}^{+}$, then the optimal $I_{G} \in \Gamma_{P}^{+} \cap \hat{I}$ where $\hat{\mathrm{I}}=\left\{I_{G}: I_{G} \leq I\right\}$. If the processor only wants to implement $e=0$, then $I_{G} \in \hat{\mathrm{I}}$.

Given the similarity between Propositions 1 and 4, the qualitative prediction that processors will require growers to make substantial investments in new production facilities should still hold.

\section{Distribution}

Having discussed how the processor responds to new legislation through contract redesign, we are now ready to discuss the possible distributional effects of PPLD. The optimal

\footnotetext{
${ }^{12}$ A similar point was made by Lazear (1990) in the context of labor market regulation.
} 
levels of $I_{G}$ along with (12) and (13) can be substituted into the processor and grower's objective functions (1) and (4) to obtain expected profits.

PROPOSITION 5: The expected profits to the processor and grower from implementing effort levels $e=1$ and $e=0$ in the shadow of PPLD are:

$$
\text { a) } \begin{aligned}
\pi_{e=1 P} & =v\left[p_{h} y-c\right]-I-\max \left\{0, \frac{v p_{l} c}{\Delta p}-v I\right\} \\
u_{e=1 P} & =\max \left\{0, \frac{v p_{l} c}{\Delta p}-v I\right\} \\
\text { b) } \pi_{e=0 P} & =v p_{l} y-I \\
u_{e=0 P} & =0 .
\end{aligned}
$$

A comparison of Proposition 5(a) to Proposition 2(a) can provide insight into the redistributive effects of PPLD. When the LL constraint is not binding, then from 2(a), we have $\pi_{e=1}=v\left[p_{h} y-c\right]-I$ and $u_{e=1}=0$; and from 5(a), we have $\pi_{e=1 P}=v\left[p_{h} y-c\right]-I$ and $u_{e=1 P}=0$. Thus, the expected profits from 2(a) and 5(a) converge so that PPLD is not redistributive. However, if the LL constraint is binding, then the processor cannot contract around PPLD, leaving the grower with rents. It is clear from 2(a) and 5(a) that the channel through which PPLD has impact is through grower rents. Hence, the existence of grower rents is a necessary condition for redistributive effects to exist. A sufficient condition is for the rents to differ across policy regimes. Thus, if expected damages under PPLD is different from expected damages under existing law, then the profit functions in 5(a) and 2(a) will diverge so that PPLD will be redistributive. For example, note from 2(a) and 5(a) that $u_{e=1}=\frac{v p_{l} c}{\Delta p}+(1-v) s D-I$ and $u_{e=1 P}=\frac{v p_{l} c}{\Delta p}-v I$. Thus, $u_{e=1 P}-u_{e=1}=(1-v)(I-s D)$, 
which is positive if $I>_{s} D$. In other words, if PPL damages are higher than expected damages under existing contract law, then the grower's expected profit increases.

COROLLARY 1: When contracting frictions cause the LL constraint to bind, then if $I>_{S} D$, the grower's expected profit will increase under PPLD while the processor's expected profit will decrease. The reverse is true if $I<s D$.

When enforcement errors are high ( $s$ is small), then $I>_{s} D$ is more likely. Thus, PPLD is most beneficial to growers when enforcement costs are high. However, if existing contract law functions well ( $s$ is near one) and expectation damages are awarded, then $I<_{s} D$ is possible in which case growers might be better off under existing contract law.

Finally, when the processor chooses to implement $e=0$, damages have no impact on the profits of either growers or processors. The logic is that, if the processor does not need to incentivize high effort, there are no LL rents. But we have seen that the impact of PPLD primarily operates through LL rents.

Ex Ante Efficiency

Proposition 3 outlined the conditions under which the processor chooses high effort, which is ex ante efficient. The introduction of PPLD alters these conditions.

PROPOSITION 6: In the shadow of PPLD, the processor implements $e=1$ if

a) $\Delta p y \geq c+\max \left\{0, \frac{p_{l} c}{\Delta p}-I\right\}$

and

b) $v\left[p_{h} y-c\right]-I+\max \left\{0, \frac{v p_{l} c}{\Delta p}-v I\right\} \geq 0$.

Comparing Proposition 6 to Proposition 3 provides insights into how a PPLD might affect efficiency. Recall that the inequality in Proposition 3(a) acts like an "IC constraint" for 
the processor to implement high effort. Once PPLD is introduced, the inequality in Proposition 3(a) changes to the inequality in Proposition 6(a). Thus, a key issue is whether 6(a) is more relaxed than 3(a). If it is more relaxed, then PPLD reduces the cost of implementing high effort thereby moving outcomes toward first best. Note that if the LL constraint is not binding, then PPLD has no impact since the two inequalities converge. A divergence only occurs when there are contracting frictions that force the LL constraint to bind. In this case, first best is not achieved under either regime, but one might want to know whether efficiency is higher under existing law or PPLD. To determine this, note that the left-hand side of Proposition 3(a) and 6(a) are identical, but the right-hand sides diverge under binding LL constraints. The inequality with the larger right-hand side implies lower efficiency as it is further away from the first best condition $\Delta p y \geq c$.

Comparing right hand sides, note that $c+\frac{p_{l} c}{\Delta p}-I>c+\frac{p_{l} c}{\Delta p}+\frac{(1-v)}{v} s D-\frac{I}{v}$ if $I>s D$.

Thus, if expected damages under existing law is lower than PPL damages, then PPLD results in lower efficiency as processors face greater liability costs.

Recall that the condition in Proposition 3(b) is analogous to a "participation constraint" for the processor in that if this constraint is violated, the processor finds it unprofitable to contract for high effort. The introduction of PPLD changes 3(b) to the inequality in Proposition 6(b). These inequalities are identical except for the terms $\max \left\{0, \frac{v p_{l} c}{\Delta p}+(1-v) s D-I\right\}$ in 3(b) and $\max \left\{0, \frac{v p_{l} c}{\Delta p}-v I\right\}$ in 6(b). The former is greater than the latter if $I>s D$. Thus, if $\mathrm{LL}$ is binding and $I>s D$, then PPLD makes it more 
expensive for the processor to contract in the first place, which might decrease social efficiency by reducing the number of contracting opportunities in the marketplace.

COROLLARY 2: PPLD is less ex ante efficient than existing contract law if $I>s D$.

To summarize, the relative efficiency of PPLD vis-à-vis existing contract law depends on (1) whether there are contracting frictions; (2) the size of enforcement errors; and (3) the size of court awarded damages under existing law. Without contracting frictions, PPLD is unlikely to decrease efficiency. However, if contracting frictions exist, then efficiency depends on whether PPL damages exceed expected damages under existing law. If existing law is highly imperfect and/or courts are reluctant to award large damages, then PPLD might actually decrease efficiency as it increases processors' expected liabilities, making it less profitable for processors to offer contracts that incentivize high effort. ${ }^{13}$

\section{Endogenous Relationship Specific Investments}

So far, the analysis has been carried out under the assumption that the level of total investment $I$ is exogenous. This section examines the impact of PPLD if $I$ is endogenous so that the processor can specify not only the share $I_{G}$ but also $I$ as part of the contract. Suppose that technology constraints only requires a minimal investment of $\underline{I}$. Then a question of interest is whether the processor will require $I>\underline{I}$. A processor may

\footnotetext{
13 These results depend on the assumption that processors cannot charge growers "entry fees" for contracting opportunities. Carmichael (1985) suggests that when agents earn rents, the principal should be able charge an entry fee that is weakly less than the rents. By extracting the rents, the processor can always implement $e=1$. Intuitively, when the processor implements high effort, it may have to pay LL rents. But if the processor can extract the rent with an entry fee, then implementing high effort is not costly to the processor. While entrance fees have theoretical appeal, there are reasons why they may not be relevant for agricultural contracting. First, one rarely observes entrance fees in actual agricultural contracts. Second, some economists provide empirical arguments against entry fees. Dickens, et. al. (1989) suggest that "...implicit limits on bonding and upfront payments reflects society's unwillingness to enforce bonding contracts." Brown, Falk and Fehr (2004) show that even in experimental settings, subjects rarely use entry fees.
} 
want to do this because, by Remarks 1 and 2, a higher level of $I_{G}$ can potentially reduce LL rents. Given the constraint $I_{G}+I_{P}=I$, a higher level of $I$ gives the processor more flexibility to increase $I_{G}$, which can potentially serve as a proxy entry fee to facilitate ex ante efficiency (see footnote 13). Of course, to make the problem interesting, we must assume that $\frac{v p_{l} c}{\Delta p}>\underline{I}$ so that grower rent is guaranteed to exist under the minimal investment level for all values of $s$ and $D .{ }^{14}$

To determine the levels of $I_{G}$ and $I$ that the processor would endogenously specify in a contract, it is useful to start with an intuitive discussion. Note that the processor's profits for a given level of $I$ and $I_{G}$ is

$$
\pi_{e=1}\left(I_{G}, I\right)=v\left[p_{h} y-c\right]-I-\max \left\{0, \frac{v p_{l} c}{\Delta p}+(1-v) s D-I_{G}\right\}
$$

where $I=I_{P}+I_{G}$ and $I \geq \underline{I}$. Recall from Proposition 1 that when $I \in \Gamma^{-}$, then the processor can increase its profits by increasing $I_{G}$ until $I_{G}=I$. Increasing $I_{G}$ is profitable to the processor in two ways. First, it reduces LL rents, $\frac{v p_{l} c}{\Delta p}+(1-v) s D-I_{G}$, without causing the grower to decrease effort, which leaves total surplus unchanged but shifts a higher fraction of the surplus to the processor. This does not affect the grower's participation constraint as the participation constraint will not bind until LL rents are completely eliminated. Thus, so long as LL rents are positive, an increase in $I_{G}$ is a costless way for the processor to extract grower rents. Second, an increase in $I_{G}$ means

\footnotetext{
${ }^{14}$ Note that if no LL rents exist, the analysis becomes trivial as there is no need for entry fees.
} 
that the processor can decrease its own investment $I_{P}$ while maintaining total investment at $I$. Hence, the processor has an incentive to expand $I_{G}$ until $I_{P}=0$.

When $I$ is endogenous, the processor has the option of increasing $I$ above the technologically determined level of investment, $\underline{I}$. At first, this may appear attractive as it gives the processor the flexibility to relax the constraint $I_{G} \leq I$ so that it can increase $I_{G}$ and extract more LL rents. However, there is a key difference between this case and the case where $I$ is exogenous. When $I$ is exogenous, an increase in $I_{G}$ implies that the processor can reduce its own investment of $I_{P}$ due to the constraint $I=I_{P}+I_{G}$. However, when $I$ is endogenous, an increase in $I$ does not necessarily imply that $I_{P}$ can be reduced as the entire constraint $I=I_{P}+I_{G}$ is relaxed. Specifically, given the assumption $\frac{v p_{l} c}{\Delta p}>\underline{I}$, we know from Proposition 1 that at $I=\underline{I}$, we have $I_{G}=I$ which implies that $I_{P}$ is already at zero. Hence, while an increase in $I$ allows the processor to increase $I_{G}$ to extract LL rents, it no longer provides the processor with the benefit of reducing $I_{P}$. As a consequence, the processor's incentive to increase $I$ is weaker than the case where $I$ is exogenous. To see this more clearly, consider the derivative

$$
\left.\frac{d \pi_{e=1}\left(I_{G}, I\right)}{d I_{G}}\right|_{I_{G}=I=\underline{I}}=-\frac{\partial I}{\partial I_{G}}-(1-v) s \frac{\partial D}{\partial I_{G}}+1=\underbrace{-1-(1-v) s \frac{\partial D}{\partial I_{G}}}_{\text {marginal cost of increasing } I_{G}} \underbrace{+1}_{\text {marginal benefit }} .
$$

Note from (15) that there is both a benefit and a cost to marginally increasing $I_{G}$. The marginal benefit is reflected by a reduction in LL rents. The marginal cost is comprised of two components. First, an increase in $I_{G}$ via an increase in $I$ implies that there is a 
reduction in total surplus (recall that total surplus is given by $v\left(p_{h} y-c\right)-I$ ). Also note that the processor's profit is total surplus minus any LL rents. Hence, the processor maximizes profits by minimizing LL rents while maximizing total surplus. Thus, while increasing $I$ facilitates the reduction of LL rents, it reduces total surplus, which erodes the processor's incentive to increase $I$. Second, an increase in $I_{G}$ might also increase the processor's expected liabilities via the term $(1-v) s D$. Specifically, with reliance damages, the term $-(1-v) s \frac{\partial D}{\partial I_{G}}=-(1-v) s<0$. In this case, (15) is negative so the processor will minimize $I$ by setting $I^{*}=\underline{I}$. Note that this is not an issue under expectation damages ( $D=\frac{p_{l} c}{\Delta p}$ ) because an increase in $I_{G}$ has no impact on $D$ so we have $-(1-v) s \frac{\partial D}{\partial I_{G}}=0$. This implies that (15) becomes zero so that the processor is indifferent about raising $I$ above $\underline{I}$ as any savings in LL rents will be offset by a decrease in surplus. PROPOSITION 7: If $\frac{v p_{l} c}{\Delta p}>\underline{I}$ then under existing contract law and expectation damages, the processor chooses $I^{*} \in\left(\Gamma^{-} \cup\left\{\frac{v p_{l} c}{\Delta p}+(1-v) s D\right\}\right) \cap \underline{I}$ where $\underline{I}=\{I: I \geq \underline{I}\}$ and grower rents are weakly positive. Under reliance damages, we have $I^{*}=\underline{I}$ and grower rents are positive.

Now consider the case where PPLD is introduced. Under PPLD, $s=1$ and $D=I_{G}$ so the analysis of the PPLD case is fairly straightforward as it is nearly identical with the non-PPLD case with reliance damages. That is, with $s=1$ and $D=I_{G}$, (15) becomes 


$$
\left.\frac{d \pi_{e=1}\left(I_{G}, I\right)}{d I_{G}}\right|_{I_{G}=I=\underline{I}}=-(1-v)<0
$$

which implies that the processor will seek to minimize $I$ by setting $I^{*}=\underline{I}$.

PROPOSITION 8: If $\frac{v p_{l} c}{\Delta p}>\underline{I}$, then under PPLD, the processor always chooses $I^{*}=\underline{I}$ and the grower earns rents.

Now that the optimal choice of $I$ has been determined, the processor and grower's expected profit can be specified to determine distribution under each policy regime.

PROPOSITION 9: The expected profits to the processor and grower from implementing effort levels $e=1$ and $e=0$ when $I$ is endogenous are:

1. Under existing contract law,

$$
\text { a) } \begin{aligned}
\pi_{e=1} & =v\left[p_{h} y-c\right]-\frac{v p_{l} c}{\Delta p}-(1-v) s D \\
u_{e=1} & =\frac{v p_{l} c}{\Delta p}+(1-v) s D-I^{*} \\
\text { b) } \quad \pi_{e=0} & =v p_{l} y-\underline{I} \\
u_{e=0} & =0 .
\end{aligned}
$$

2. Under PPLD,

$$
\begin{aligned}
\pi_{e=1 P} & =v\left[p_{h} y-c\right]-\frac{v p_{l} c}{\Delta p}-(1-v) \underline{I} \\
u_{e=1 P} & =\frac{v p_{l} c}{\Delta p}-v \underline{I} \\
\text { b) } \quad \pi_{e=0 P} & =v p_{l} y-\underline{I} \\
u_{e=0 P} & =0 .
\end{aligned}
$$

Proposition 9 can be used to determine how profits might be affected by PPLD. A simple comparison of expected profits across policy regimes shows that, if expected damages under existing contract law is lower than under PPLD so that $s D<\underline{I}$, then grower profit is higher and processor profit is lower under PPLD. 
COROLLARY 3: With endogenous $I$, if $I>s D$, then the grower's expected profit will increase under PPLD while the processor's expected profit will decrease.

Note that this conclusion is very similar to Corollary 1 so that the endogeneity of $I$ has little impact on the earlier results. The next proposition outlines efficiency conditions under the endogeneity of $I$.

PROPOSITION 10: The processor implements $e=1$ if the following conditions hold:

1. Under existing contract law,
a) $\Delta p y \geq c+\frac{p_{l} c}{\Delta p}+\frac{(1-v)}{v} s D-\frac{I}{v}$
b) $v\left[p_{h} y-c\right]-\frac{v p_{l} c}{\Delta p}-(1-v) s D \geq 0$.

2. Under PPLD,
a) $\Delta p y \geq c+\frac{p_{l} c}{\Delta p}-\underline{I}$
b) $v\left[p_{h} y-c\right]-\frac{v p_{l} c}{\Delta p}-(1-v) \underline{I} \geq 0$.

The inequalities in Proposition 10, 1(a) and 2(a), can be compared to the benchmark condition $\Delta p y \geq c$ to determine whether $e=1$ is more likely to be implemented under existing contract law or PPLD. The policy regime that yields conditions closes to $\Delta p y \geq c$ is the more efficient. Similarly, the inequalities in Proposition 10, 1(b) and 2(b), can be compared to the first best condition $v\left(p_{h} y-c\right)-\underline{I} \geq 0$.

Focusing first on conditions 1(a) and 2(a), note that they are identical except for the right-hand side of each inequality. The right-hand side of 1(a) deviates from the righthand side of the first best condition $\Delta p y \geq c$ by the amount $\frac{p_{l} c}{\Delta p}+\frac{(1-v)}{v} s D-\frac{I}{v}$ whereas 
the right-hand side of 2(a) deviates by the amount $\frac{p_{l} c}{\Delta p}-\underline{I}$. Hence, if

$\frac{p_{l} c}{\Delta p}+\frac{(1-v)}{v} s D-\frac{I}{v} \leq \frac{p_{l} c}{\Delta p}-\underline{I}$, then PPLD increases the cost of implementing $e=1$. It is straightforward to show that this true if $s D \leq \underline{I}$.

In comparing $1(\mathrm{~b})$ and $2(\mathrm{~b})$, given the assumption $\frac{v p_{l} c}{\Delta p}>\underline{I}$, one only has to determine whether $1(\mathrm{~b})$ or 2(b) is more "relaxed" to determine which inequality is closer to the first best condition $v\left(p_{h} y-c\right)-\underline{I} \geq 0$. The regime that delivers the more relaxed inequality may promote more contracting opportunities for growers. For example, if $v\left[p_{h} y-c\right]-\frac{v p_{l} c}{\Delta p}-(1-v) s D \geq v\left[p_{h} y-c\right]-\frac{v p_{l} c}{\Delta p}-(1-v) \underline{I}$ holds, then it is more profitable to contract for high effort under existing contract law. This is true if $s D<\underline{I}$.

COROLLARY 4: PPLD is less ex ante efficient than existing contract law if $s D<\underline{I}$.

To summarize, there are two important take away lessons in the case of endogenous $I$. First, a rational processor has very weak incentives to require investments that exceed the technologically required level. Thus, it is unlikely that a processor will extract away grower rents for bonding or entry fee purposes. Intuitively, any reduction in LL rents is offset by a reduction in total surplus due to an increase in $I$. Since the processor's profit is essentially total surplus minus any LL rents, there is a one-to-one tradeoff between LL rents and total surplus which erodes the processor's incentive to increase $I$. Second, whether PPLD will reduce efficiency vis-à-vis existing contract law is similar to the results obtained with an exogenous $I$. 


\section{Conclusion and Discussion}

A general policy implication of the study is that the enactment of PPLD might not have uniform efficiency and distributional consequences across all agricultural subsectors and regions. The likely consequences will depend on whether contracting frictions exist, the size of enforcement errors under existing contract law, and the size of damages courts are likely to award under existing law. It is important for policy makers to bear these determinants in mind when formulating projections about the likely effects of PPLD. For instance, if contracting frictions caused by credit market imperfections or wealth constraints are minimal, distortions will also be minimal as processors are able to restructure contracts to accommodate the legislation. Under these conditions, PPLD might be an effective and non-distortionary way of protecting grower's investments. However, complications arise when contracting frictions reduce the ability of contractors to restructure contracts to accommodate exogenous policy changes. In this case, the enactment of PPLD will have both efficiency and redistributive effects, though the direction and magnitude depend on additional factors. When enforcement errors are high and/or courts are reluctant to award large damages under existing contract law, then expected damages under existing law are likely to be lower than PPL damages. This will increase expected profits of growers who obtain contracts, while reducing efficiency. This scenario is likely to hold in sectors or regions where it is excessively costly for growers to sue processors for damages or in regions where courts determine growers to be "merchants" so that they are held to a higher standard of knowledge about commercial law. Moreover, court interpretations of whether growers are entitled to damage awards can also 
depend on whether contracts are long term (e.g. in the hog sector) or short term (e.g. in the broiler sector). In short, when growers find it difficult to collect damages under existing law, then PPLD will protect growers, but may decrease efficiency. However, in sectors and regions where courts are effective at enforcing existing contract law, the introduction of PPLD may actually decrease grower welfare while increasing efficiency.

This study represents one of the first formal attempts at understanding recently proposed produced protection legislation, and is not without limitations. First, because the analysis involves formal economic modeling, it emphasizes generalizable principles rather than concrete, sector specific details. However, this research might provide a theoretical basis for sector specific empirical work that focuses on the determinants of the efficiency and redistributive effects of PPLD. Second, this study does not address issues related to double-sided moral hazard where processors can take actions to minimize quality problems related to the inputs that they supply to growers. According to some surveys, growers are concerned about the quality of inputs they receive from processors during the production process (Farmers' Legal Action Group, Inc. 2001). Thus, an important extension of this study is to incorporate double-sided moral hazard by assuming that processor actions can influence input quality. Finally, this study focuses primarily on formal contracts where all aspects of performance are governed by explicit incentives. However, in practice, contractual relationships typically involve a mixture of formal contracts and informal agreements and expectations. Thus, future research might focus on whether results remain robust in environments characterized by relational contracting. 


\section{References}

Allen, D.W., and D. Lueck. 1995. "Risk Preferences and the Economics of Contracts." American Economic Review 85: 447-451.

Barton, J.H. 1972. “The Economic Basis of Damages for Breach of Contract.” Journal of Legal Studies 1:277-304.

Brown, M., A. Falk, and E. Fehr. 2004. "Relational Contracts and the Nature of Market Interactions." Econometrica 72:747-780.

Carmichael, L. 1985. "Can Unemployment be Involuntary? Comment." American Economic Review 75:1213-1214.

Cunningham, D.L. 2005. "Guide for Prospective Contract Broiler Producers.” The Cooperative Extension Service, University of Georgia College of Agr. and Env. Sciences. Bull. No. 1167/Minor Revision, September.

Demougin, D., and D.A. Garvie. 1991. "Contractual Design with Correlated Information Under Limited Liability." Rand Journal of Economics 22:477-489.

Dickens, W., L. Katz, K. Lang, and L. Summers. 1989. "Employee Crime and the Monitoring Puzzle.” Journal of Labor Economics 7:331-347.

Erkal, N. 2007. "Buyer-Supplier Interaction, Asset Specificity, and Product Choice." International Journal of Industrial Organization, 25: 988-1010.

Farmers’ Legal Action Group, Inc. 2001. “Contract Broiler Production - The Legal Context and Recommendations." In Assessing the Impact of Integrator Practices on Contract Poultry Growers, Farmer's Legal Action Group, Inc., St. Paul, MN, September.

Hamilton, N.D. 1995. A Farmer's Legal Guide to Production Contracts. Philadelphia, 


\section{PA: Farm Journal.}

Innes, R. 1990. "Limited Liability and Incentive Contracting With Ex-ante Action Choices." Journal of Economic Theory 52:45-67.

Knoeber, C.R. 2000. "Land and Livestock Contracting in Agriculture: A Principal Agent Perspective.” In B. Bouckaert and G. de Geest, eds. Encyclopedia of Law and Economics, United Kingdom: Edwin Elgar Publishers, pp. 1133-1153.

Laffont, J.J., and D. Martimort. 2002. The Theory of Incentives: the Principal-Agent Model. Princeton, NJ: Princeton University Press.

Lazear, E. 1990. “Job Security Provisions and Employment.” Quarterly Journal of Economics 105:699-726.

Lee, M, S.Y. Wu, and M. Fan. 2008. "Balancing Grower Protection against Agency Concerns: An Economic Analysis of Contract Termination Damages.” Journal of Agricultural and Resource Economics 33:154-168.

Lewin-Solomons, S.B. 2000. "Asset Specificity and Hold-Up in Franchising and Grower Contracts: A Theoretical Rationale for Government Regulation?” Working Paper, Dept. of Econ., Iowa State University.

Moeller, D. 2003 “Livestock Production Contracts: Risks for Family Farmers.” Farmer's Legal Action Group, Inc., St. Paul, MN, March 22.

Vukina, T., and P. Leegomonchai. 2006. "Oligopsony Power, Asset Specificity, and HoldUp: Evidence from the Broiler Industry." American Journal of Agricultural Economics 88: 589-605.

Wu, S.Y. 2006. "Contract Theory and Agricultural Policy Analysis" Australian Journal of Agricultural and Resource Economics 50: 490-509. 
Wu, S.Y. 2010. “AJAE Appendix: Producer Protection Legislation and Termination Damages in the Presence of Contracting Frictions. " Unpublished manuscript. Available at: http://ageconsearch.umn.edu/ 